The Proceedings follow the general plan of the conference, which was divided effectively into two parts. The first three days, July 4-6, were for the specialists and consisted of parallel sessions devoted to pion and nucleon physics, strange particle physics, cosmic-ray and highenergy physics, and the theory of elementary particles. Following the week-end, which was free of scheduled lectures, there were three days of plenary sessions at which the results of the previous sessions were intended to be summarized and put into perspective for the conference as a whole by 'rapporteurs', one for each subject division. Naturally, with so much information reported and discussed, the 'rapporteurs' had no easy task and their lectures to the plenary sessions as given in the Proceedings show that many quite openly admitted their inability to summarize or survey the work presented at the conference. They dealt generally with one or other aspects of the particular topic assigned to them. Nevertheless, with the whole of the Proceedings available to the reader there should be no difficulty in finding out the progress reported in any special field.

Prof. V. F. Weisskopf, director-general of CERN, gave the concluding address and in his brief remarks surveyed in a masterly and clear fashion the progress achieved both experimentally and theoretically in highenergy physics during the years between 1960 and 1962 . Many new facts had emerged. Results obtained from scattering experiments of nucleons by nucleons or pions by nucleons show that the nucleon at very high energies gets moro diffuse and largor so far as scattering with strongly interacting particles is concerned. It implies the absence of a core. The various groups of isobars, in particular the baryons and thoir oxcited states, now seem to fit in well with the simple quantum numbers, but it is still unknown what this means. There are indications, too, that the list of the excited states is limited, unlike the excited states of the hydrogen atom. The discovery of the existence of two neutrinos has opened up a new field of research, neutrino physics, and a special session of the conference was devoted to the neutrino exporiment, which was described by M. Schwartz. Members of Columbia University, New York, and of the Brookhaven National Laboratory, conducted the experiment in which it demonstrated that the neutrons emitted in $\pi-\mu$ decay differs from that emitted in nuclear $\beta$ decay. The increasing amount of evidence that the muon is equal to the electron in all its properties except that of mass, and other dotails about weak interactions, such as whether the $\Delta Q=\Delta S$ rule holds, or whether the isotopic spin changes by more than $\frac{1}{2}$, leave, however, weak interaction theory still much where it was in 1960 , in spite of more than 300 papers on the subject during the two years between the conferences. This is the conclusion arrived at by L. B. Okun of the Institute of Theoretical and Experimental Physics, Moscow, who acted as 'rapporteur' for the sessions on weak interactions (theoretical). His report is followed by a bibliography for the period. January 1961-May 1962 in which are listed some 320 papers.

Prof. Weisskopf concludes with the remark that we do not understand the moaning of what we observe. "We are trying, not without success, to introduce analogies and ways of speaking. It could be that all we have found follows from field theory. The theoretical situation is problematical but full of interesting ideas. The experimental situation is very much better than anyone would have guessed two years ago. The world within the nucleon is much richer and much more interesting than we ever expocted."

The Proceedings lists 357 sciontists in addition to thoso from CERN as having attended the conference and altogether some 760 people participated in the conference either as authors of papors or in tho discussions. At the first conference in 1951 there were only about 50 participants. It is difficult to forecast what will be the number at the next conference in 1964 at the Joint Institute for Nuclear Research, in Dubno, and whether the progress to be reported will be significant and worthy of the very large effort now devoted to high-energy physics. The next Proceedings will doubtless have to be published in two volumes.

S. Weintroub

\section{TRANSISTOR COMPENDIUM}

\section{Der Transistor}

Physikalische und technische Grundlagen. Von Dr. H. Salow, Prof. Dr. H. Beneking, Dr. H. Krömer und Dr. W. v. Münch. (Technische Physik in Einzeldarstellungen, Band 15.) Pp. viii +426 . (Berlin, Göttingen, Heidelberg: Springer-Verlag; München: J. F. Bergmann, 1963.) Dm. 82.

THS book is in effect a collection of four monographs, each of which was written by one of the authors, as follows: (1) "Physical Background of 'Transistors" (Krömor, pp. 73); (2) "Technological Background of Transistors" (Salow, pp. 137); (3) "General Circuit Theory of Transistors" (Beneking, pp. 139); (4) "Physical and Technical Properties of Transistors" (von Münch, pp. 64).

Part 1 starts immediately with the electron energy band model, then passes rapidly through carrier statistics and current transport phenomona to the theory of the plane $p-n$ junction diode and $p-n-p$ transistor. In both cases, as is to be expected, the author deals with both the 'diffusion' and 'drift' type of device, although the treatment is necessarily condensed. Finally, some of the ways in which the behaviour of practical transistors depart from the simple low-injection-level, one-dimensional theory are discussed.

In the second part, there is a relatively detailed account of the methods of growing cystals of germanium and silicon and of the various etchants which are used for surface treatment: there are some beautiful photographs of etch pits. This is followed by an account of the various processes by which transistors of difforent geometrical construction and impurity profile are made, the reasons for the different geometries being given. It is arguable, however, whether or not too much emphasis has been given to this part. Although a considerable amount of detail has been presented, it is obviously not enough to enable an uninitiated reader either to grow a crystal or to make a device; it would therefore seem better to err on the side of giving too little rather than too much. In Part 3 the author deals with the usual topics of bias stabilization, small-signal parameters, and equivalent circuits (with a bias to the hybrid- $\pi$ ) and then proceeds to examine amplifiers, with particular reference to stability, and oscillators. Finally, switching properties are considered.

The last part is of limited scope, dealing in the main with circuits for the measurement of the $h$-parameters in the low-frequency and high-frequency bands, and the effect of temperature on static characteristics. There is a brief reference to the measurement of noise at low fre. quencies. The section is concluded, out of character, with a series of short descriptions of 'other junction devices'.

In general it can be said that each author has contributed something usoful to the whole, but that the work lacks cohesion and the emphasis is not evenly distributed. One would like to have read more of avalanche breakdown and noise, which are very cursorily dealt with, and less of crystal growing. Part 1 could havo been expanded considerably with advantage. None the less, the book is not without value as it stands. Although it cannot be regarded as a useful introductory book to the serious student of transistors, it will no doubt be a very useful adjunct to such a book-for readers of German. F. J. HYDE 